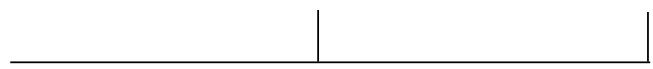

Rev. Latinoam. Psicopat. Fund., São Paulo, v. 14, n. 2, p. 383-389, junho 2011

Retorno à questão judaica

Elisabeth Roudinesco

Tradução de Claudia Berliner

Rio de Janeiro: Zahar, 2010

\title{
A propósito da obra Retorno à questão judaica: diálogo com Elisabeth Roudinesco*
}

Betty Bernardo Fuks

Em tempos de penúria, quando alguns insistem em desmentir o fato da catástrofe que inundou de sangue a civilização, a Shoá; quando outros tantos sustentam que o Estado de Israel é o único referente identitário possível para os judeus ou, ao contrário, colocam em questão sua legitimidade; e ainda quando muitos insistem em julgar o conflito Israel/Palestina no eixo maniqueísta do bem e do mal; um livro que se propõe interrogar a questão judaica mais além dessas barreiras ideológicas é extremamente bem-vindo. Tanto mais porque a autora, Elisabeth Roudinesco, estabelece ao longo dos capítulos uma rigorosa advertência contra o exercício da crueldade e da violência social.

O título da obra - Retorno à questão judaica - é um convite a pensar o tema na fronteira entre o social e o singular subjetivo.

* Este texto tem por base uma palestra proferida na Casa de Rui Barbosa (RJ) por ocasião do "Ciclo de Identidade e Referências: novas definições", em 4.7.2010. 
Entre os rastros da história e os traços do sujeito do inconsciente, a autora empreende ampla e corajosa reflexão, a partir das categorias de judaísmo - o que recobre o conjunto das tradições culturais e religiosas do povo judeu - da judaicidade - aquilo que designa expressamente o grupo judeu em sua totalidade demográfica, dispersa em várias comunidades através do mundo -; e da escuta de sua própria judeidade e a de pensadores com os quais dialogou sobre a impossível "identidade" judaica.

Neste ponto, quando Roudinesco usa este termo que me é caro - judeidade -, preciso sublinhar que, na minha leitura, judeidade quer dizer o modo como cada sujeito vive o seu judaísmo, a sua própria condição de ser judeu. Trata-se de algo a ser interminavelmente definido e sempre construído, num processo sem fim, jamais concluído, independentemente do fato da religião judaica contar ou não para o sujeito. Portanto, um projeto subjetivo que transgride a simples observância dos modelos do passado, escapa às contingências relativas ao mero nascimento e determina a inserção do sujeito no futuro. Consequentemente, um devir ligado ao desejo: realidade processual e não simplesmente o processo de transformação de alguma coisa em outra, que alcançaria um determinado ser finalizado, regido pelo princípio de identidade e sinônimo de objetividade e presença.

Por exemplo, o devir-mulher implica a noção da impossibilidade de um ser final, pois não há A Mulher na qual o sujeito possa se transformar de uma vez por todas, mesmo quando se é mulher. No devir-judeu, o que se coloca é a impossibilidade do ser judeu; isto é, na expressão devir-judeu é preciso colocar a ênfase sobre o devir e não sobre o judeu. Essa não identidade consigo mesmo evidentemente não é exclusiva da feminilidade ou da judeidade. Mas quem ousará dizer que estas figuras não são paradigmáticas do processo subjetivo de tornar-se outro?

Considero muito feliz a escolha da editora Zahar de ter emoldurado as teses do livro, já na própria capa: uma composição feita a partir do Muro das lamentações, último vestígio do Templo Sagrado, construído pelo rei Salomão e destruído pelos babilônios. Conforme a tradição, foi a partir dessa perda que os judeus se engajaram no exercício de suportar e ultrapassar a vivência de cortes e privações territoriais, através da prática de leitura e escrita de sua história. $\mathrm{O}$ Antigo Testamento passa a aglutinar o povo disperso na diáspora. De fato, o termo diáspora significa "estar disperso entre os povos", "estar fora de", ou, ainda, "não pertencer a". Na própria palavra - diáspora - já se encontra a ideia de ruptura, que toca os fundamentos da existência do povo judeu e que na modernidade trará algo de inédito ao vir-a-ser da judeidade.

A imagem do Muro das lamentações também evoca as inúmeras contradições entre os descendentes de Jacó, a quem Deus ordenou no deserto: "E te lembrarás que fostes escravo no Egito. Eis porque te ordeno respeitar o estrangeiro". 
Elisabeth Roudinesco critica, com a liberdade dos que não se curvam a nenhuma intimidação, todos os atos de violência que contradizem este mandamento: o fundamentalismo sacro; os ideais nacionalistas de um núcleo rígido de identidade judaica fixada em termos de fidelidade a Israel; e a força militar israelense, por vezes desmedida, frente às ameaças à segurança do país.

Dona de reconhecida cultura, Roudinesco indaga o enigma do judeu a partir das múltiplas "pátrias" que ela própria frequenta e a respeito das quais se mostra vigilante; quer se trate da diáspora judaica, de Israel, da França e até mesmo da psicanálise. Sua escrita me causou o desejo de refletir sobre essas questões que penso serem de grande valia nas discussões sobre as novas definições de identidades e referências. Particularmente as questões tocam no ponto em que me encontro muito próxima da autora, já que compartilhamos a honra de sermos discípulas de Freud.

Mas o que tem a ver a questão judaica com a psicanálise? Criada num período histórico - a modernidade vienense - em que a experiência do tornar-se outro explodia em vários campos da cultura, a invenção freudiana trouxe uma contribuição decisiva para o desenvolvimento de uma crítica contra toda e qualquer forma de preconceito. Sem adentrar nas consequências da criação do conceito de inconsciente, acrescento que a marginalidade social e cultural pessoalmente sentida por Freud, enquanto judeu da diáspora, mostrou-se, segundo suas próprias declarações, fundamental na tarefa de obter forças para enfrentar e vencer as resistências à psicanálise.

Levar a condição de exílio, inscrita na história do povo judeu, à sua potência criadora máxima foi, para Freud, parte integrante da invenção de uma judeidade estranha ao que, convencionalmente, era designado como judeu, no Ocidente. As escolhas e estratégias a partir das quais ele a praticou definiram-se e se desenvolveram paralela e articuladamente à invenção da psicanálise, a expressão maior de seu devir-judeu. Mesmo tendo se afastado da religião de seus pais e impedido sua mulher, filha de rabino, de praticar rituais judaicos, quando se perguntava ou era indagado sobre o que constituía a "identidade judaica", afirmava ser impossível responder a essa questão; embora se reconhecesse como judeu no fato de estar constantemente disposto a travar uma luta perpétua com a "maioria maciça" e homogeneizada, fosse ela externa ou interna ao próprio judaísmo - fato bastante relevante. Definir a identidade judaica implicaria, para Freud, expulsar de si toda a dimensão de alteridade e negar a própria ideia de que a identidade independe do sexo, da classe, ou do país de origem do sujeito.

"O eu não é senhor em sua própria casa". Esta foi a conclusão à qual Freud foi levado com sua descoberta do inconsciente. Nada contou mais para ele do que esta descoberta radicalmente subversiva com a qual atingiu o narcisismo da hu- 
manidade moderna. Daí a necessidade de se retornar a ela incessantemente, para fazer presente a ideia de que identidade nunca é dada ou completa, ela pressupõe diferenças - as identificações inconscientes. Com isso também afastamos a psicanálise dos que querem torná-la um pensamento essencialista.

É no contexto dessa teorização que a leitura de "O homem Moisés e o monoteísmo", que Freud publicou em vida, adquire um peso maior quando se quer pensar o modo como ele se colocou diante da questão judaica. Penso que devemos somar a esta consideração a contribuição maior que a psicanálise tem a dar ao entendimento da formação de grupos e das massas; e à critica das novas políticas de identidade. ${ }^{1}$

Freud começa a escrever "Moisés...", algum tempo depois que seus livros foram queimados nos Autos da fé na Universidade de Berlim. Num primeiro momento, respondeu à demonstração de vandalismo com humor judaico: "Como a humanidade evolui!... Na Idade Média, eu teria sido queimado e não meus livros!", ironizou, numa clara alusão às fogueiras da Santa Inquisição. Na ocasião não poderia imaginar o pior: suas quatro irmãs foram assassinadas nas câmaras de gás, como outros milhões de judeus. Diante da barbárie e do iminente retorno do ódio ao judeu, Freud recolhe das cinzas as letras mais importantes de seus textos e com elas dá início a obra que atravessará com ele o exílio a Londres. E para assombro de muitos e revolta de outros, judeus e não judeus, extrai do livro do Êxodo o estrangeiro que deu origem à familiar "identidade" judaica: Moisés, o egípcio.

O outro como constituinte do mesmo é condição da identidade. Por essa razão é que o Moisés de Freud surge instituindo que a vida comum de um grupo unido de seres idênticos é resultado do desmentido do outro em si mesmo. Freud aposta na construção identitária do povo judeu mais além do etnocentrismo, o que não significa que tenha colocado qualquer obstáculo à invenção da judeidade. Afinal, para a psicanálise, não existe identidade fixa e imutável, mas sim a pluralidade de diferentes vínculos identificatórios estabelecidos ao longo da vida. Para Freud, o sujeito pode também elevar-se sobre todas essas identificações "na medida em que possui um fragmento de independência e originalidade" (Freud, 1921).

1. Compreender o ódio ao outro por pequenas disputas através do paradigma do judeu, foi um dos motores da escrita de "Moisés". Freud coloca a discussão sobre o antissemitismo no registro do "narcisismo das pequenas diferenças": a massa, quando capturada pelas malhas fascinantes dos jogos de identificação com o líder, persegue o outro movida pela crença na hegemonia do eu e pelo esvaziamento da dimensão da alteridade no grupo. Neste sentido, entendo que a psicanálise pode contribuir à compreensão da problemática segregacionista ensejando uma nova perspectiva sobre a pluraridade que relativize quaisquer pretensões essencialistas das massas e de determinados grupos. 
Moisés, o egípcio, inventa o judeu, então, todo judeu é um egípcio, isto é, está para além da raça, da língua ou do sangue.

Na Europa pré-Segunda Guerra, quando a política de construção de identidades ideais fazia crescer o totalitarismo, a psicanálise lega ao mundo uma crítica implacável à ideologia que, em conluio com a ciência da raça, visava reduzir o homem a seu destino biológico, destruindo o nó civilizatório entre nome e carne, entre verbo e corpo, para fazer da filiação puro vínculo de sangue. O que Freud contrapõe a essa tentativa de rompimento com o simbólico é a ideia de que a transmissão se faz pela narrativa de uma verdade histórica, expressão que define a relação singular que cada cultura e/ou sujeito é chamada a viver em relação à herança recebida das civilizações/e ou gerações anteriores. Ou seja, a exigência de singularidade é a única garantia de transmissão de uma tradição ou de um pensamento.

Compreender o ódio ao outro por pequenas disputas através do paradigma do judeu, o ancestral unheimlich ${ }^{2}$ das massas, foi, sem dúvida, um dos motores da escrita de "Moisé...". E embora a maioria das reflexões ao longo do texto tenha girado em torno da história judaica, ao contrário do que se costuma dizer, Freud não tinha a menor intenção de "responsabilizar" o judaísmo pelo antissemitismo. Na verdade, o que ele faz é realocar a discussão sobre o antissemitismo no registro do narcisismo das pequenas diferenças. Assim, pode situar o ódio ao judeu, o racismo e o segregacionismo na dimensão agressiva do sujeito frente à diferença do outro, o horror à diferença ex-tima, isto é, a aversão do sujeito ao que lhe é mais íntimo e mais-externo.

Quando da edição de "Moisés...”, em 1939, a questão judaica caminhava para a Solução Final, o Holocausto. Freud não viveu para testemunhar este acontecimento abominável. Mas sensível à política de seu tempo e conhecedor da história do Homem, teorizou sobre o alcance do poder da crueldade humana e do caráter sem fim de uma das faces da pulsão de morte, a pulsão de destruição, o desejo que habita o homem de matar, assassinar, humilhar, torturar, abusar sexualmente e explorar o outro.

Como combater o antissemitismo, este sintoma social que retorna virulentamente neste momento, legítima preocupação que levou Roudinesco a escrever o seu livro?

Após a vivência dos campos de extermínio, Lacan fez o esforço de conceitualizar e significar esta ruptura da humanidade para a qual só existe a saída de contornar o trauma e a impossibilidade de dizê-lo. O trauma da Segunda Guerra só é passível de transmissão pela escrita, principalmente a artística, que faz repensar o "histórico" e o impossível de se dizer, conforme lembra Roudinesco. A

2. Termo que, para Freud, significa um momento em que um fato ou alguma coisa pode ser, ao mesmo tempo, familiar e estranho. 
essa função ética da escrita podemos associar as elaborações lacanianas sobre identificação e a exclusão do outro. Para encurtar o que teria por dizer, dado o adiantado da hora, faço minhas as palavras do cientista político Stravakakis, em seu empenho de pensar a política a partir da teoria lacaniana: "Ao gritarmos Todos somos judeus!, Todos vivemos em Chernobyl! Todos somos refugiados!", elevamos estes sintomas sociais, que contêm a verdade excluída do campo social, ao lugar do universal. Chegamos, assim, ao ponto de nossa identificação comum ao que é, no momento, sustentado mediante a exclusão ou eliminação.

O mesmo ocorrerá se for possível postular que a democracia só terá uma posição mais firme de combate ao antissemitismo se reconhecer que o Holocausto é parte verdadeira de toda a história e não apenas judaica: o assassinato do próprio homem. Quando descobrimos o que sucedeu na Segunda Guerra aos homossexuais, doentes mentais, ciganos e comunistas, e não somente aos judeus, estamos capacitados a dizer: "Posso ser eu a próxima vítima". Essa estratégia de identificação ao outro (identificação ao sintoma) na análise contemporânea da política se aproxima bastante da ideia de Lévinas (2000, p. 48-49), ${ }^{3}$ segundo a qual a subjetividade passa pela capacidade do homem de assumir a responsabilidade por outrem. Trata-se, então, de afirmar a própria identidade pela deposição do eu soberano em favor do outro em nós mesmos, o estrangeiro, o estranho.

Assim sendo, por que não dizer que a responsabilidade de Israel, pelos palestinos, passa pela possibilidade de destituição de sua soberania, ato capaz de permitir aos israelenses dizerem: “Todos somos palestinos!". E vice-versa: os palestinos precisarão se despojar da própria identidade para gritar "todos somos israelenses", numa declaração performativa para o cessar das ameaças terroristas que não conseguem nada mais do que atrair a retaliação em massa.

Voltando ao livro de Roudinesco, compartilho com seu pensamento de que, para se fortalecer como Estado democrático, Israel precisa se reaproximar daquilo que permitiu aos judeus resistir às catástrofes e o que constitui sua universalidade: a ideia de que nenhum homem pode ser reduzido à sua comunidade, às suas raízes e a seu território. Mas também gostaria de lembrar, neste momento, as palavras de Jalaludín Rumi, poeta e místico sufi do século XIII, que traduzem a experiência da cultura islâmica da busca da verdade por meio do amor e devoção a Deus.

Se a imagem de nosso amado está no templo

Então é um erro encantador andar em volta da mesquita

Se na mesquita o seu perfume não está presente

3. Segundo Lévinas (2000), “... o tempo não é fato de um sujeito único, mas a própria relação do sujeito com outrem” (p. 48). Sobre este tema, ver também Coelho Junior, 2008. 
Então ela nada mais é do que uma sinagoga

E se na sinagoga sentimos a fragrância da união com ele

Então essa sinagoga é nossa mesquita.

(Rumi, J. Apud, Lewis 1996, p. 16-17)

Portanto, cada povo tem uma forma própria de reconhecer a existência do outro. Como psicanalista, é o que tenho a dizer no momento, na esperança de que árabes e judeus encontrem uma solução pacífica e democrática para este conflito doloroso, no qual as tentativas feitas pela paz, infelizmente, foram até aqui repudiadas pelos governantes israelenses e palestinos. O que nos dá a medida dos ideais antidemocráticos de ambos. Porque, afinal, ser democrata implica no eterno aprendizado de reconhecimento da diferença e no contínuo e interminável exercício da responsabilidade pelo Outro.

\section{Referências}

Coelho Junior, N. Da fenomenologia à ética como filosofia primeira: notas sobre a noção de alteridade no pensamento de E. Lévinas. Estudos e Pesquisa em Psicologia, Rio de Janeiro, ano 8, n. 2, p. 213-223, $1^{\circ}$ semestre de 2008.

Freud, S. (1921). Psicologia das massas e a análise do eu. In: Edição Standard Brasileira das Obras Psicológicas Completas de Sigmund Freud. Rio de Janeiro: Imago, 1976. V. XXIII.

. (1939[1934-1938]). Moisés e o monoteísmo. In: Edição Standard Brasileira das Obras Psicológicas Completas de Sigmund Freud. Rio de Janeiro: Imago, 1976. V.XXIII.

LÉvinAs, E. (1961). Ética e infinito. Lisboa: Edições 70, 2000.

Lewis, B. O Oriente Médio: do advento do cristianismo aos dias de hoje. Rio de Janeiro: Jorge Zahar, 1996.

StaVAKakis, Y. Lacan y lo político. Buenos Aires: Prometeo, 2007.

\section{Betty Bernardo Fuks}

Psicanalista e professora do Mestrado em Psicanálise, Saúde e Sociedade da Universidade Veiga de Almeida (Rio de Janeiro, RJ, Brasil); Autora de Freud e a judeidade; a vocação do exílio (Rio de Janeiro: Zahar, 2000).

Av. Rui Barbosa, 500/602

22250-020 Rio de Janeiro, RJ

e-mail: betty_fuks@hotmail.com 